RELATION BETWEEN DUODENAL ULCER AND BLOOD GROUP IN PEOPLE OF THE UDAIPUR REGION OF INDIA

The high frequency of peptic ulceration in the Udaipur region of India (Malhotra, 1964; Sharma, Singh, Shah, and Gangwal, 1967) and a possible causal relationship between the blood group and ulcer formation (Clarke, Evans, McConnell, and Sheppard, 1959) led us to make an extensive survey of the blood groups of the people of the region and the patients.

The blood groups of 3,799 subjects (controls) were either obtained from the blood bank at Udaipur or determined by us and of a test group of 186 patients with peptic ulcer other groups taken together for normals and patients the difference is highly significant statistically $\left(\chi^{2}\right.$ is calculated to 23.9554 which for 1 degree of freedom gives $P<0.001)$. This suggests that there is some dependence or association between blood group and peptic ulcer with preponderance in group $\mathbf{O}$. But as blood group $\mathbf{O}$ is not predominant in the control series, it cannot be the main cause of ulceration in this region.

We are grateful to Dr P. D. Mathur, Principal, R.N.T. Medical College, Udaipur, Dr P. K. Mathur, officer in charge of the blood bank, and Dr M. S. Gambhir, officer in charge of the record room, for permitting us to collect and report the information.

TABLE I

BLOOD GROUP FREQUENCIES IN CONTROLS AND TESTS

\begin{tabular}{lrrrr}
$\begin{array}{l}\text { Blood } \\
\text { Group }\end{array}$ & $\begin{array}{l}\text { Number in } \\
\text { Control Group }\end{array}$ & $\begin{array}{c}\text { Number in } \\
\text { Test Group }\end{array}$ & $\begin{array}{c}\text { Percentage } \\
\text { Difference }\end{array}$ \\
\hline A & $879(23 \cdot 14 \%)$ & $32(17 \cdot 20 \%)$ & $-5 \cdot 94$ \\
B & $1,346(35 \cdot 43 \%)$ & $42(22 \cdot 58 \%)$ & $-12 \cdot 85$ \\
O & $1,300(34.22 \%)$ & $99(53 \cdot 23 \%)$ & $+19 \cdot 01$ \\
AB & $274(7 \cdot 21 \%)$ & $13(6.99 \%)$ & -0.22 \\
Total & 3,799 & $100 \cdot 00$ & $186 \quad 100 \cdot 00$ & -
\end{tabular}

operated on in the General Hospital, Udaipur, during the years 1963-65. All of them had ulcer confirmed histopathologically.

Our observations are recorded in Table I together with the percentage difference between the test and the control group which shows a high incidence of peptic ulcer in people of blood group $\mathrm{O}$. The mean relative incidence of peptic ulcer in persons of blood group $\mathrm{O}$ compared with the incidence of persons in other groups is $2 \cdot 19$. Comparing the relative proportions of group $\mathrm{O}$ and the

\section{EFFECT OF INTRAVENOUS CALCIUM IN GASTRIC SECRETION}

I would like to draw your attention to a few points concerning the article published in Gut $(8,592)$ by Dr R. A. Smallwood on the effect of intravenous calcium on gastric secretion.

The results of this work are not in accordance with a previous work I have done and to which the author has referred. He ascribed the discrepancy between our results to a rapid administration of the intravenous calcium in my cases. This, however, is not true. I would like to suggest other explanations based on more scientific grounds.

1 The amount of calcium administered by $\mathrm{Dr}$ Smallwood to his patients ranged between $420 \mathrm{mg}$, taking the average body weight as $70 \mathrm{~kg}$, as in patients 12 and 19 , and $2.0 \mathrm{~g}$ as in patients 7,8 , and 13-18.

The amount of calcium given to my patients was $5.355 \mathrm{~g}$, ie, 2.7 to 13 times the amount given to $\mathrm{Dr}$ Smallwood's patients.

The idea behind my work was to simulate the condition in which calcium is administered intravenously: calcium administered intravenously is never as little as $420 \mathrm{mg}$.

2 Dr Smallwood's cases are 14 duodenal ulcers, two hyperparathyroidism, two chronic cholecystitis, and

\section{REFERENCES}

Clarke, C. A., Evans, D. A. P., McConnell, R. B., and Sheppard, P. M. (1959) Secretion of blood group antigens and peptic ulcer Brit. med J. 1, 603-607.

Malhotra, S. L. (1964). Peptic ulcer in India and its aetiology. Gut, $5,412-416$

Sharma, B. N., Singh, S. V., Shah, D. R., and Gangwal, K. C. (1967). Prevalence of peptic ulcer in Udaipur region. J. Indian med. Ass., 48, 170-174.

D. C. SHARMA, R. C. JAIN, AND S. S. DAVE Department of Biochemistry and Pathology, RNT Medical College, Udaipur, India

only two normal. All my cases were normal. It goes without saying that the response of stomachs of duodenal ulcer patients to stimuli of acid and pepsin secretion cannot be considered normal. Similar hyperparathyroid patients cannot be considered normal in two respects: the continuous increased parathyroid hormone which was proved, in my department and elsewhere, to be a stimulus to gastric acidity, and the prolonged hypercalcaemia present.

3 The accordance of my results with animal experiments, carried on canine animals, is, I believe, ascribed to the attainment of nearly equal blood levels of calcium in my cases to those reported in animal experiments.

Thus to my mind, in the two normal cases of $\mathrm{Dr}$ Smallwood, excluding all the duodenal ulcer and hyperparathyroid not being comparable to my cases, the results he obtained differ from my results and animal results due to the small dose of calcium given to these patients, 630 and $945 \mathrm{mg}$ in cases 3 and 1 respectively.

M. ESSAM FIKRY, Gastro-Enterology and Liver Research Centre, Faculty of Medicine, Alexandria University, Alexandria, Egypt, UAR 